\section{Electrocardiographic indices of clinically healthy Chios sheep}

\section{Aliasghar Chalmeh, Iman Saadat Akhtar, Mohamad Hadi Zarei, Mehrdad Badkoubeh}

School of Veterinary Medicine, Shiraz University, Iran

\section{Abstract}

Information regarding normal electrocardiographic features of different breeds of animals can help veterinarians to detect any abnormalities in cardiac electrical activities. The current research was conducted to present the normal electrocardiographic indices of clinically healthy Chios ewes and lambs. The electrocardiograms were recorded from clinically healthy Chios ewes ( $\mathrm{n}=27 ; 2-3$ years old) and lambs ( $\mathrm{n}=20$; 4-6 months old) by using base apex lead system. T and QRS-duration in lambs were significantly lower than adult Chios ewes. The electrocardiographic amplitudes in lambs were lower than ewes, non-significantly. P-R, R-R, Q-T and S-T intervals in Chios lambs were significantly lower than ewes. No normal sinus rhythm was detected in Chios lambs. The proportion of sinus arrhythmia and sinus tachycardia in lambs was significantly more than ewes. Sino-atrial block was also detected in lambs. Based on the presented data it could be stated that aging can affect electrocardiographic findings of Chios sheep. Finally, our results will provide a good basis for judging the electrocardiograms in base apex lead system of Chios lambs and ewes.

\section{Introduction}

The heart electrical activities can be recorded over a period of time by electrocardiography, as a non-invasive procedure. The heart beats caused from depolarization and repolarization of the myocardium, which are detectable by electrocardiography and finally record and produce electrocardiograms (ECGs). Recording ECG in large animals has several indications such as evaluating the heart rate and rhythm, size of cardiac chambers, myocardial damages, electrolyte imbalances and drugs side effects. 1

There are several electrocardiographic lead systems in large animals to record ECGs contain bipolar (I, II, III, base-apex, X, Y and Z of the orthogonal lead system) and unipolar leads (aVF, aVR, aVL, thoracic); but the recorded waves by these leads in each animal's breed, size, body type and sex are different from others and these factors should not affect the ECGs. ${ }^{2}$ Base apex lead in large animals has not the complications in other leads and can record the clear and large waves and animal movements have minimum effects on the recordings. 1,3

The Chios is known as a breed of semi-fat tailed domestic sheep which originated from the Greek island of Chios and they are commonly bred for their milk production. ${ }^{4}$ Several researchers studied the electrocardiographic parameters in clinically healthy sheep and goats by base apex lead and leads other than the base apex; $;^{5-9}$ but according to the author's knowledge, the study on normal electrocardiographic indices of clinically healthy Chios sheep is lacking. Hence, the current study was performed to present and clarify the normal electrocardiographic characteristics of Chios lambs and ewes tracing by base apex lead system. The data presented here may be used as guideline to evaluate the cardiac electrical activities of this breed.

\section{Materials and Methods}

The present study was performed in March 2015 on clinically healthy Chios ewes ( $n=27 ; 2$ 3 years old) and lambs ( $n=20 ; 4-6$ months old), around Shiraz, Fars province, southwest of Iran. All animals were grazing in a green pasture with free access to water and shade. The animals were examined prior to ECG recordings and proved to be clinically healthy. None of the ewes and lambs used in this study had any clinical signs of heart diseases (edema, jugular distension or pulsation and cardiac murmurs), coughing and exercise intolerance.

The ECGs were recorded on a bipolar base apex lead, using limb lead I. Animals were kept standing without any sedation and minimum restraint, also. When animals got calm (decreased panting behavior and muscle tremors), the ECGs were recorded, using alligator-type electrodes which were attached to skin after cleaning it with ethanol and applying electrocardiographic jelly to improve skin contact. The positive electrode (left arm) was placed over cardiac apex in the fifth left intercostal space at the level of the elbow, the negative electrode (right arm) was placed in the left jugular furrow at the top of heart base, the neutral electrode (right foot) was used on the skin of thoracic inlet and the ground was placed on the dorsal spine or another site away from the heart. ${ }^{1}$ All ECGs were obtained in a single channel electrocardiographic machine (Kenz-line EKG 110, Suzuken Co., Ltd., Japan) with paper speed of $25 \mathrm{~mm} / \mathrm{sec}$ and calibration of $10 \mathrm{~mm}$ equal to $1 \mathrm{mV}$. The precision of dura-
Correspondence: Aliasghar Chalmeh, Department of Clinical School of Veterinary Medicine, Sciences, Shiraz University, P0 Box 71345, Shiraz, Iran.

Tel.: +98.711.36138700 - Fax: +98.711.32286940.

E-mail: achalmeh81@gmail.com

Key words: Electrocardiogram; normal index; Chios sheep.

Contributions: the authors contributed equally.

Conflict of interest: the authors declare no potential conflict of interest.

Received for publication: 5 May 2015. Accepted for publication: 17 June 205.

This work is licensed under a Creative Commons Attribution NonCommercial 3.0 License (CC BYNC 3.0).

(C) Copyright A. Chalmeh et al., 2015

Licensee PAGEPress srl, Italy

Veterinary Science Development 2015; 5:5986 doi:10.4081/vsd.2015.5986

tion was 0.02 second and amplitude was 0.05 $\mathrm{mV}$. The ECGs were examined to evaluate normal electrocardiographic indices and cardiac arrhythmias, subsequently.

Mean and standard deviation (SD) were calculated for all studied electrocardiographic indices. Two independent samples t-test was used to detect statistical differences between ewes and lambs about similar electrocardiographic parameter. Fisher's exact test was used to detect any proportional distribution of arrhythmias between ewes and lambs. All data were analyzed by using SPSS software (SPSS for Windows, version 20, SPSS Inc, Chicago, Illinois). $\mathrm{P}<0.05$ was considered statistically significant.

\section{Results}

The normal electrocardiographic indices of clinically healthy Chios sheep are presented in Tables 1 to 3. T and QRS-duration in lambs were significantly lower than adult Chios ewes $(\mathrm{P}<0.05$; Table 1). The electrocardiographic amplitudes in lambs were lower than ewes, non-significantly ( $\mathrm{P}>0.05$; Table 2). P-R, R-R, $\mathrm{Q}-\mathrm{T}$ and $\mathrm{S}$-T intervals in Chios lambs were significantly lower than ewes $(\mathrm{P}<0.05$; Table 3$)$. No normal sinus rhythm was detected in Chios lambs. The proportion of sinus arrhythmia and sinus tachycardia in lambs was significantly more than ewes. Sino-atrial block was also detected in lambs (Figures 1 and 2). 


\section{Discussion}

Electrocardiography can be used as a clinical method of choice to assess the cardiac problems regarding heart electrical activities and the initiation and conduction of waves of depolarization and repolarization. ${ }^{3}$ There are several literature about electrocardiographic studies on different breeds of the small ruminants, ${ }^{8,9}$ but information regarding the base apex electrocardiography of clinically healthy Chios sheep was lacking. The data in basic electrocardiographic indices of this breed could be used as reference values to assess heart electrical activities.

The base apex lead appears to be most useful in measuring conduction times (i.e., durations of component deflections, intervals, and segments) because the origins and terminations of deflections could be identified easily. ${ }^{3}$ It has been reported that the base apex lead gave the least variable ECG tracings in all the animals; furthermore, the $\mathrm{P}$ waves, QRS complexes, and $\mathrm{T}$ waves in the base apex lead had the highest mean amplitude of all the leads recorded. ${ }^{3}$ It seems that our study on Chios ECG parameters in base apex lead system may be helpful in standardizing the base apex lead of this breed.

The conductive properties of the body mass of ruminants, attributable to the volume of the gastrointestinal tract, influence the distribu- tion of body surface potentials comprising the ECG. ${ }^{3}$ This may explain the differences among different ECG parameters between the different ages in our study (Tables 1 to 3 ). The gradual development of body mass may cause difficulty in reaching the waves to the body surface due to relative electrical insulation by increasing body mass and decrease of amplitude in adults. ${ }^{10}$

In the present study the electrocardiographic durations and intervals were increased significantly during aging. The transition time of heart electrical impulses produces durations and intervals. It may be stated that the smallest cardiac size and more superficial purkinje fibers in lambs in comparison with ewes can create lowest durations and intervals in younger ones. It could be suggested that as the mass of heart in larger animals became larger in the process of growth, the duration of transfer of cardiac electrical activity also increases. ${ }^{11}$ The amplitude of $\mathrm{P}, \mathrm{R}, \mathrm{S}$ and $\mathrm{T}$ waves recorded in the studied sheep were not followed a specific pattern during aging. The changing of amplitudes presumably could be due to a high degree of synchronized ventricular polarization passing in any given direction. Furthermore, alterations between heart situation and attached positive electrode can change amplitudes. This may be also due to the presence of high degree of synchronization of depolarization of individual myocardial fibers. At the birth, significant hypoxemia and acidaemia may develop. ${ }^{12}$ Moreover, after the onset of breathing, the change in pulmonary vascular resistance with expansion of the lungs results in a great increase in pulmonary blood flow, accompanied by a rise in left atrial pressure. ${ }^{13,14}$ This generates distension of the atrial walls and stretching of the atrial muscles and these might be related to the occurrence of cardiac arrhythmias. ${ }^{15}$ It was suggested that the development of hypoxia was relative to the arrhythmias. It was considered that a hypoxic condition during delivery may contribute to the occurrence of neonatal arrhythmias in horses. 16 Belenky et al. 17 demonstrated that the hypoxic carotid chemoreflex, in lamb, is present at birth, but has a significantly longer response time than later in the newborn period. Moreover, the CNS-mediated ventilatory response to hypoxia was also noted to be present in the newborn animal through at least 12 days or longer times of postnatal age. ${ }^{17}$

Cardiac arrhythmias also occur commonly in association with gastrointestinal disorders in the dairy cow and less commonly in the horse and resolve without specific antiarrhythmic treatment when the primary gastrointestinal disorder is corrected. ${ }^{1}$ At birth the rumen is a rudimentary nonfunctional sac. Normal development of the rumen requires the establishment of a viable microbial population and the formation of volatile fatty acids. ${ }^{18}$ Establishment of ruminal microbial fermentation begins between two to four weeks of age

Table 1. The durations (sec) of standard electrocardiographic indices (mean \pm standard deviation) of base apex lead of clinically healthy Chios ewes and lambs.

\begin{tabular}{lcccc} 
Age groups & P-duration & T-duration & QRS-duration & S-duration \\
Lambs $(\mathrm{n}=30)$ & $0.020 \pm 0.005$ & $0.029 \pm 0.007$ & $0.095 \pm 0.005$ & $0.010 \pm 0.001$ \\
Ewes $(\mathrm{n}=30)$ & $0.021 \pm 0.007$ & $0.039 \pm 0.006$ & $0.125 \pm 0.017$ & $0.011 \pm 0.002$ \\
\hline P-value & 0.091 & $0.026^{*}$ & $0.019 *$ & 0.089 \\
\hline
\end{tabular}

*Significant differences between groups at similar indices $(\mathrm{P}<0.05)$.

Table 2. The amplitudes $(\mathrm{mV})$ of standard electrocardiographic indices (mean \pm standard deviation) of base apex lead of clinically healthy Chios ewes and lambs.

\begin{tabular}{lcccc} 
Age groups & P-amplitude & T-amplitude & R-amplitude & S-amplitude \\
Lambs $(\mathrm{n}=30)$ & $0.052 \pm 0.016$ & $0.110 \pm 0.057$ & $0.054 \pm 0.012$ & $0.261 \pm 0.089$ \\
Ewes $(\mathrm{n}=30)$ & $0.055 \pm 0.010$ & $0.122 \pm 0.050$ & $0.059 \pm 0.018$ & $0.272 \pm 0.065$ \\
\hline P-value & 0.162 & 0.132 & 0.092 & 0.076 \\
\hline
\end{tabular}

Table 3. The intervals (sec) of standard electrocardiographic indices (mean \pm standard deviation) of base apex lead of clinically healthy Chios ewes and lambs.

\begin{tabular}{lcccc} 
Age groups & PR-interval & RR-intervalQT-interval & ST-interval & \\
Lambs $(\mathrm{n}=30)$ & $0.045 \pm 0.008$ & $0.203 \pm 0.032$ & $0.071 \pm 0.014$ & $0.060 \pm 0.014$ \\
Ewes $(\mathrm{n}=30)$ & $0.056 \pm 0.008$ & $0.263 \pm 0.040$ & $0.112 \pm 0.019$ & $0.090 \pm 0.049$ \\
\hline P-value & $0.035^{*}$ & $0.002^{*}$ & $0.001^{*}$ & $0.022^{*}$ \\
\hline
\end{tabular}

*Significant differences between groups at similar indices $(\mathrm{P}<0.05)$. 
as a result of the initiation of solid feed intake. ${ }^{19,20}$ Changes in physiological states of gastrointestinal tract, feed intake and alterations in energy metabolism, may affect the cardiac performance and changes in ECG parameters. Furthermore, changes in food regimen and electrolyte profile may affect cardiac musculature and its activation.

The results of the present study showed that sinus tachycardia and sinus arrhythmia were the most frequent cardiac arrhythmias in the studied animals (Figure 2). Sinus tachycardia means an increase in heart rate that is initiated by the sino-atrial node. The term sinus tachycardia is used to describe an increase in heart rate caused by detectable influences such as pain, excitement, exercise, hyperthermia, a fall in arterial blood pressure or the administration of adrenergic drugs. ${ }^{1}$ The heart rate returns to normal when the influence is removed or relieved. It may be suggested that the higher heart rates might be due to stress and excitation resulting from isolation of lambs from their dams as well, but since the animals were placed in a quiet state, it is unlikely to be the origin for this higher heart rate in studied animals. Because there were no clinical signs of cardiac problems (edema, jugular distension or pulsation) in all studied animals, this cardiac rhythm irregularity could be categorized as physiologic arrhythmias. Matsui et al.21 reported an elevation of the heart rate in newborn pony foals with administration of a combined blockade with atropine and propranolol. These observations indicate the possibility of high vagal activity in the newborn Thoroughbred foal at birth. ${ }^{15}$ Sustained tachycardia is an important clinical problem in the fetus and newborn. The physiological properties of the fetal and neonatal myocardium make it intrinsically more vulnerable to high heart rates.22 Fetal tachycardia is an important cause of fetal morbidity and mortality. 23 The rate of fetal tachycardia is of no real help in defining the mechanism, as most tachycardia occurs at about higher than 120 beats/min and average of this parameter was 170 beats/min at the time of ECG recordings.

Sinus arrhythmia was also seen frequently in Chios ewes and lambs (Figure 2). This arrhythmia has been reported in cattle which have been deprived of food or had anorexia due to some gastrointestinal problems. ${ }^{24,25}$ None of the animals with sinus arrhythmia in this study had any clinically obvious systemic problems or were suffering from anorexia. High vagal tone could be suggested as the cause of this arrhythmia in any ages of these animals. ${ }^{26}$ Sinus arrhythmia is a normal physiological arrhythmia that occurs at slow resting heart rates and is associated with variation in the rate of discharge from the sino-atrial node associated with variation in the intensity of vagal stimulations. It is commonly correlated with respiration so that the discharge rate and heart rate increase during inspiration and decrease during expiration. Sinus arrhythmia is more clinically obvious in tame sheep and goats. ${ }^{1}$ It may be possible to link the genesis of the sinus tachycardia and sinus arrhythmia in apparently healthy lambs to the increased load imposed on the heart or the fluctuation of the sympathetic or parasympathetic tone associated with excessive exertion during the stage of the birth. ${ }^{27}$

Sino-atrial block was also detected in Chios lambs (Figures 1 and 2). In sino-atrial block the sinus node fails to discharge or its impulse is not transmitted over the atrial myocardium. It is associated with the complete absence of heart sounds, of jugular atrial wave and of an arterial pulse for one beat period. The underlying rhythm is regular unless sinus arrhythmia is present. In the ECG there is complete absence of the P, QRS and T complex for one beat. The distance between the preblock and postblock $\mathrm{P}$ waves is twice the normal P-P

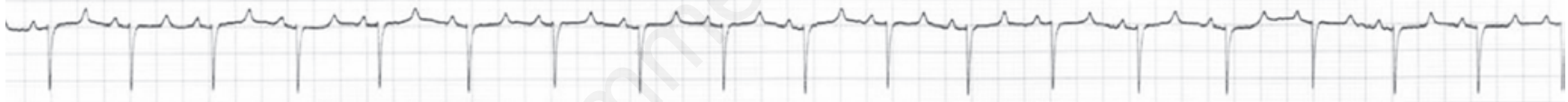

A

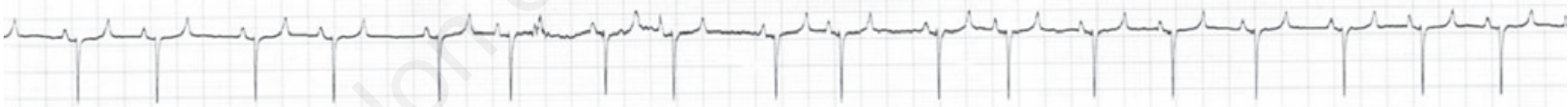

B

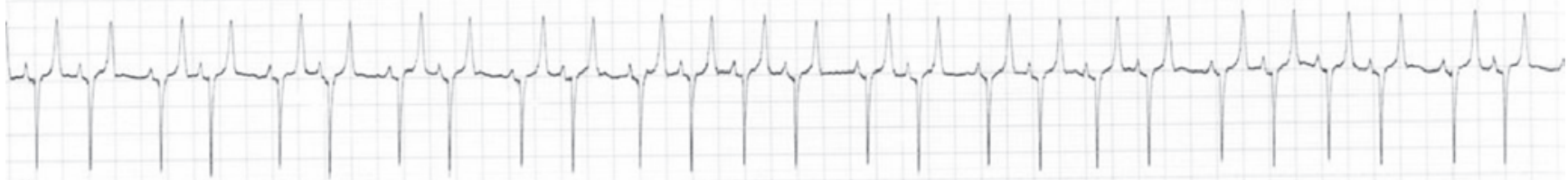

C

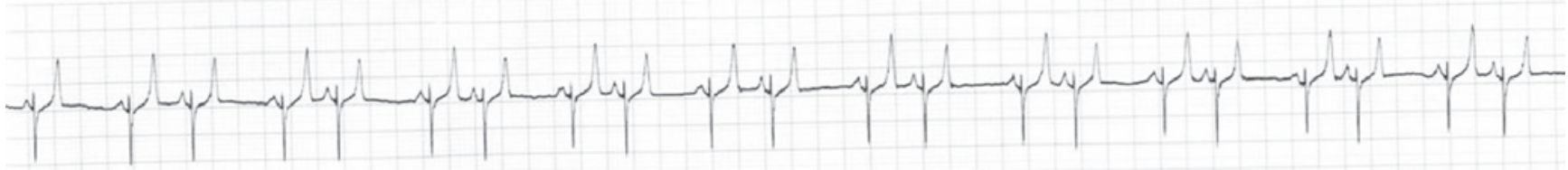

D

Figure 1. The electrocardiograms tracing from clinically healthy Chios sheep by base apex lead system (paper speed $25 \mathrm{~mm} / \mathrm{sec}$, sensitivity $10 \mathrm{~mm} / \mathrm{mV}$ ). A: Normal sinus rhythm in an ewe; B: Sinus arrhythmia in a lamb; C: Sinus tachycardia and sinus arrhythmia in a lamb; D: Sino-atrial block in a lamb. 


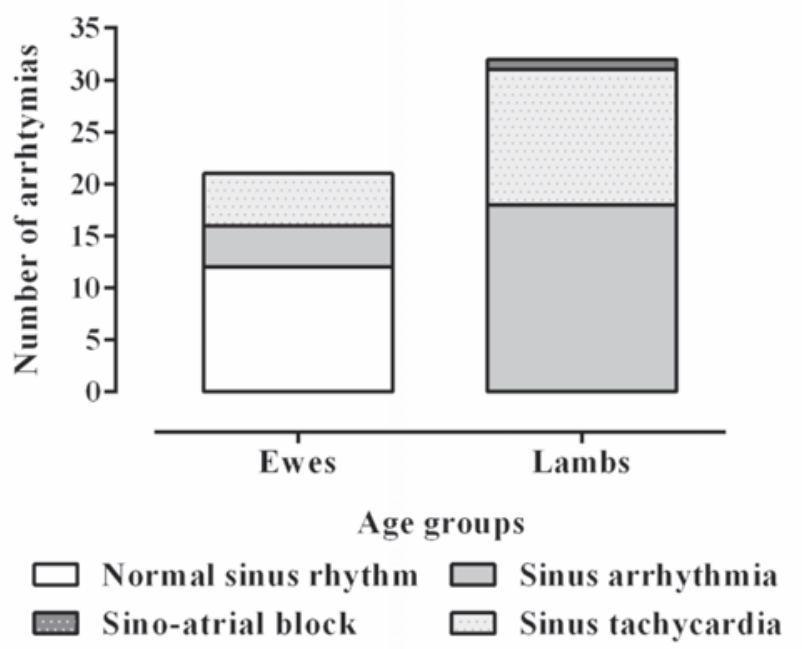

Figure 2. Distribution and proportion of cardiac arrhythmias in clinically healthy Chios ewes $(n=27)$ and lambs $(n=20)$ tracing by standard base apex lead system electrocardiography.

interval or sometimes slightly shorter. This arrhythmia is not uncommon in fit racing horses at rest and can be induced in horses and cattle by procedures that increase vagal tone. ${ }^{1}$ Since, there were no clinical abnormalities in lambs which had sino-atrial block, it can be stated that this arrhythmia is categorized as physiological cardiac rhythm irregularities in Chios lambs.

\section{Conclusions}

In conclusion, it is obvious that these data will provide a good basis for judging the ECGs in base apex lead system of Chios lambs and ewes. It could be stated that aging can affect electrocardiographic findings. Furthermore, it may be suggested that the cardiac arrhythmias observed in the clinically healthy Chios ewes and lambs in this study could be accepted as the physiological arrhythmias and so no treatment is necessary. Finally, the results of the present research can help veterinarians to detect any abnormalities in heart electrical performance of Chios sheep and may be used as the guideline for the assessment of any cardiac rhythm irregularities in Chios sheep suffering from cardiac problems.

\section{References}

1. Radostits OM, Gay CC, Hinchcliff KW, Constable PD. Diseases of the cardiovascular system. In: Veterinary medicine: a text book of the diseases of cattle, horses, sheep, pigs and goats. 10 $10^{\text {th }}$ ed. Philadelphia: Elsevier, USA; 2007. pp. 399438.

2. Reef VB, McGuirk SM. Diseases of the cardiovascular system. In: Smith BP, ed. Large animal internal medicine. $4^{\text {th }}$ ed. Philadelphia: Elsevier, USA; 2009. pp. 453489.

3. Santamarina G, Espino L, Suarez LM. Electrocardiographic parameters of freeranging roe deer (Capreoluscapreolus). J Zoo Wildl Med 2001;32:441-6.

4. Gelasakis AI, Valergakis GE, Arsenos G, Banos G. Description and typology of intensive Chios dairy sheep farms in Greece. J Dairy Sci 2012;95:3070-9.

5. Pourjafar M, Badiei K, Chalmeh A, et al. Cardiac arrhythmias in clinically healthy newborn Iranian fat-tailed lambs. Glob Vet 2011;6:185-9.

6. Pourjafar M, Badiei K, Chalmeh A, et al. Comparison of cardiac arrhythmias between late pregnancy and early post-partum periods in clinically healthy Iranian fat-tailed sheep. Pak Vet J 2011;31:309-12.

7. Pourjafar M, Badiei K, Chalmeh A, et al. Age-related cardiac arrhythmias in clinically healthy Iranian Najdi goats. Bulg J Vet Med 2012;15:37-43.

8. Mohan NH, Niyogi D, Singh HN. Analysis of normal electrocardiograms of Jamunapari goats. J Vet Sci 2005;6:295-8.

9. Ahmed JA, Sanyal S. Electrocardiographic studies in Garol sheep and black Bengal goats. Res J Cardiol 2008;1:1-8.

10. Kellerová E, Szathmáry V, Kozmann G, et al. Spontaneous variability and reactive postural beat-to-beat changes of integral ECG body surface potential maps. Physiol Res 2010;59:887-96.

11. Schmidt-Nielsen K. Animal physiology: adaption and environment. $6^{\text {th }}$ ed. New York: Cambridge University Press; 1997.

12 Comline RS, Silver M. Placental transfer of blood gases. Br Med Bull 1975;31:25-31.

13 Dawes GS, Mott JC, Widdicombe JC, Wyatt DG. Changes in the lungs of the newborn lamb. J Physiol 1953;121:141-62.

14. Dawes GS. Changes in the circulation at birth. Br Med Bull 1961;17:148-53.

15. Yamamoto K, Yasuda J, Too K. Arrhythmias in newborn Thoroughbred foals. Equine Vet J 1992;23:169-73.

16. Takayuki I. A study of arrhythmias in thoroughbred newborn foals immediately after birth. Jpn J Vet Res 1990;38:57.

17. Belenky DA, Standaert TA, Woodrum DE. Maturation of hypoxic ventilatory response of the newborn lamb. J Appl Physiol 1979;47:927-30.

18. Tamate H, McGilliard AD, Jacobson NL, Getty R. Effect of various dietaries on the anatomical development of the stomach in the calf. J Dairy Sci 1962;45:408-20.

19. Baldwin RLVI, Jesse BW. Developmental changes in glucose and butyrate metabolism by isolated sheep ruminal cells. J Nutr 1992;122:1149-53.

20. Baldwin RL. Sheep gastrointestinal development in response to different dietary treatments. Small Ruminant Res 2000;35:39-47.

21. Matsui K, Sugano S, Masuyuna L, et al. Alterations in the heart rate of Thoroughbred horse, pony and Holstein cow through pre- and post-natal stages. Jpn J Vet Sci 1984;46:505-10.

22. Rudolph AM. Congenital diseases of the heart: clinico-physiological considerations. Armonk, NY: Futura; 2001.

23. Wren C. Cardiac arrhythmias in the fetus and newborn. Semin Fetal Neonatal Med 2006;11:182-90.

24. Machida N, Okamoto Y, Minami S, et al. Cardiac arrhythmias in normal Holstein heifers. J Jpn Vet Med Assoc 1991;44:11769.

25. Gentile A, Guglielmini C, Cipone M. Alerazioni del ritmo cardiaco nel bovino in rapporto col digiuno. Arch Vet Ital 1993;44:100-7.

26. Rezakhani A, Papahn AA, Gheisari HR. Cardiac dysrhythmias in clinically healthy heifers and cows. Rev d Méd Vét 2004;155:159-62.

27. Machida N, Nakamura T, Kiryu K, Kagota K. Electrocardiographic features and incidence of atrial fibrillation in apparently healthy dairy cows. Zentralbl Veterinarmed A 1993;40:233-9. 